\title{
Speech-evoked Brainstem Auditory Responses and Auditory Processing Skills: A Correlation in Adults with Hearing Loss
}

\author{
Taissane Rodrigues Sanguebuche ${ }^{1}$ \\ Michele Vargas Garcia ${ }^{1}$ \\ ${ }^{1}$ Department of Speech Therapy, Universidade Federal de Santa
Maria, Santa Maria, Rio Grande do Sul, Brazil \\ Int Arch Otorhinolaryngol 2018;22:38-44.
}

\author{
Rúbia Soares Bruno ${ }^{1}$ Eliara Pinto Vieira Biaggio ${ }^{1}$
}

Address for correspondence Taissane Rodrigues Sanguebuche, Speech Therapist, Department of Fonoaudiologia, Universidade Federal de Santa Maria, Santa Maria, Rio Grande do Sul 97105-900, Brazil (e-mail: taissane.sanguebuche@outlook.com).

\begin{abstract}
Introduction The auditory system consists of sensory structures and central connections. The evaluation of the auditory pathway at a central level can be performed through behavioral and electrophysiological tests, because they are complementary to each other and provide important information about comprehension.

Objective To correlate the findings of speech brainstem-evoked response audiometry with the behavioral tests Random Gap Detection Test and Masking Level Difference in adults with hearing loss.

Methods All patients were submitted to a basic audiological evaluation, to the aforementioned behavioral tests, and to an electrophysiological assessment, by means of click-evoked and speech-evoked brainstem response audiometry.

Results There were no statistically significant values among the electrophysiological test and the behavioral tests. However, there was a significant correlation between the $V$ and $A$ waves, as well as the $D$ and $F$ waves, of the speech-evoked brainstem response audiometry peaks. Such correlations are positive, indicating that the increase of a variable implies an increase in another and vice versa.

Conclusion It was possible to correlate the findings of the speech-evoked brainstem response audiometry with those of the behavioral tests Random Gap Detection and Masking Level Difference. However, there was no statistically significant correlation between them. This shows that the electrophysiological evaluation does not depend uniquely on the behavioral skills of temporal resolution and selective attention.
\end{abstract}

\section{Introduction}

The auditory system is responsible for the sensation and perception of sound stimuli, allowing human beings to process different sounds simultaneously. This system consists of sensory structures and central connections whose functions are stimulus capture and auditory processing respectively. ${ }^{1}$

A peripheral alteration can be detected through a basic audiological assessment. An assessment at the central level, however, is performed by means of more specific behavioral and electrophysiological tests. ${ }^{1}$

Behavioral tests are designed to assess an individual's performance in situations similar to those experienced in everyday life. ${ }^{2}$ Good performance reflects the integrity of different auditory skills that are fundamental "parts" in acoustic information processing. ${ }^{3}$ Among all the skills, this study highlights temporal resolution and selective attention, which assess a lower portion of the brainstem. ${ }^{4}$ received

December 8, 2016

accepted

March 21, 2017

published online

May 31, 2017
DOI https://doi.org/

10.1055/s-0037-1603109. ISSN 1809-9777.
Copyright $\odot 2018$ by Thieme Revinter

Publicações Ltda, Rio de Janeiro, Brazil
License terms

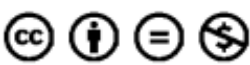


One of the electrophysiological tests available is the brainstem auditory-evoked response (BAER), which is an objective, non-invasive test, generated by the synchronism of the structures of the auditory pathway, which begins in the auditory nerve, goes through the cochlear nucleus, the superior olivary complex, the lateral lemniscus, and up to the inferior colliculus. ${ }^{5}$

The acoustic stimulus most often used in the clinical practice is the click, because it is believed that this stimulus triggers a synchronous response from a large number of neurons and evaluates, in this way, a broad spectrum of frequencies. ${ }^{6,7}$ However, other types of stimuli can be used to trigger electric responses, such as verbal stimuli. ${ }^{8}$

The use of this type of stimulus may clarify how the speech signal is processed in the brainstem, because this structure of the auditory pathway plays a fundamental role in the speech perception mechanism, which, in turn, is closely linked to the development of language and reading. 9,10

The stimuli most often used for capturing auditory brainstem responses (ABRs) with verbal stimuli, also called speechevoked ABR, is the syllable /da/, in which the consonant $/ d$ / represents the transient portion or onset, and the vowel /a/, the sustained portion or the frequency-following response (FFR). The tracing generated by this stimulus is a complex wave composed of seven peaks: $\mathrm{V}, \mathrm{A}, \mathrm{C}, \mathrm{D}, \mathrm{E}, \mathrm{F}$, and $\mathrm{O}$. The $\mathrm{V}$ and $\mathrm{A}$ waves reflect neural responses at the beginning of the stimulus, and the $\mathrm{C}$ wave represents the consonant-vowel transition, while the 0 wave represents the end of the vowel. ${ }^{11}$ Any variation in the production of this tracing, be it in the transient or in the sustained portion, is already considered an alteration, because the acoustic signal is not being encoded properly. ${ }^{12}$

Even though the sites where they are generated are not well-defined, ${ }^{7}$ some studies have highlighted the role and the clinical applicability of the speech-evoked ABR..$^{13-15}$ The results showed that it is a fast and effective test. Moreover, it does not require the conscious participation of the subject, and provides important data on neural maturation in subcortical auditory pathways. ${ }^{16}$ Thus, it can serve as a biomarker, measuring the effect of a therapeutic intervention, both in learning disorders ${ }^{17}$ and in auditory processing disorders. ${ }^{18}$

Given the aforementioned information, one can see that the behavioral and electrophysiological assessments complement each other and provide important information about the hearing process. Therefore, the objective of the present study is to correlate the findings of the speechevoked ABR with these behavioral tests: Random Gap Detection Test (RGDT) and Masking Level Difference (MLD), which respectively assess the hearing skills of temporal resolution and selective attention in adults with hearing loss.

\section{Method}

This prospective, quantitative and cross-sectional study was approved by the Research Ethics Committee under protocol number 25933514.1.0000.5346. All assessments were performed at the Outpatient Audiology Clinic of a university hospital. The subjects who agreed to participate in the study signed a free and informed consent form (FICF), which informed them about the procedures, the risks, the benefits, and the confidentiality of the research data, following all ethical principles, according to Resolution 466/12 of the Brazilian National Health Council.

The composition of the sample was based on the following eligibility criteria: both male and female subjects aged between 18 and 59 years; hearing thresholds within normal limits, as measured by the tritonal mean, with loss of up to 65 decibels $(\mathrm{dB})$ in the frequencies of $2 \mathrm{kHz}, 3 \mathrm{kHz}$ and $4 \mathrm{kHz}$, or up to moderate sensorineural hearing loss according to the referenced in the literature ${ }^{19}$; no chronic tinnitus; speaking Brazilian Portuguese as mother language; preferably righthanded subjects; having at least the $\mathrm{V}$ wave in the speechevoked ABR. Subjects were excluded when they had conductive hearing loss, asymmetric hearing thresholds, neurological disorders, chronic diseases and also if they played a musical instrument.

In order to compose the sample, the researchers contacted subjects that were on the waiting list of the Municipal Health Department for participation in the Hearing Health Program. Through the program, they receive hearing aids under concession. Users of a reference workers' health center were also contacted.

The researchers assessed 330 records of patients on the waiting list of the Hearing Health Program. However, only five of them met all eligibility criteria. Twenty-nine of the excluded patients had greater than moderate hearing loss; 17 had conductive impairment; 12 had hearing losses above $65 \mathrm{~dB}$ in high frequencies; 261 were under 18 years of age or older than 59 years; 6 had neurological disorders; and 6 had chronic tinnitus coexisting with other exclusion criteria.

At the workers' health center, 246 patient records were evaluated, but only 3 met the eligibility criteria. A total of 3 excluded patients had greater than moderate hearing loss; 4 had conductive impairment; 23 had asymmetric auditory thresholds; 9 lacked important data; 102 had auditory thresholds within the normal range; and 102 were younger than 18 years of age or older than 59 years.

All patients underwent audiological anamnesis, otoscopy, tonal and vocal audiometry and impedance audiometry, and performed behavioral tests for auditory processing: RGDT and MLD. Moreover, they underwent an electrophysiological assessment by means of click-evoked and speech-evoked ABR. It should be noted that the subjects were evaluated in a single session, but there were intervals for rest between the procedures listed for the present study.

The audiological evaluation was performed in a soundproof booth with acoustic treatment, using the following equipment: a Mikatos otoscope (Embu das Artes, Brazil); a Phonak Fonix FA-12 audiometer (Tigard, USA); TDH39 supra-aural headphones (Immitanciometer Interacoustics, Denmark); a Positivo laptop (Curitiba, Brazil) and an Interacoustics AT 235 immittance device.

The behavioral tests were chosen because they rely heavily on the brainstem for responses. More specifically, the RGDT is composed of sequences of paired pure tones, at the frequencies of $500 \mathrm{~Hz}, 1,000 \mathrm{~Hz}, 2,000 \mathrm{~Hz}$ and $4,000 \mathrm{~Hz}$. The intervals between tones range from zero to $40 \mathrm{~ms}$ in random 
order. The test was performed at 50 decibels sensation level (dBSL) and/or with the most comfortable loudness level, in binaural condition. The subjects were instructed to respond verbally if they heard one or two tones. The training track and the test tracks were applied to check the shortest interval when the individual started to identify the two tones. The analysis was made by means of the average of the four frequencies of the test. The results were considered normal when greater than or equal to $10 \mathrm{~ms}^{20}$

By contrast, the MLD test determines the hearing threshold by a pulsating pure tone of $500 \mathrm{~Hz}$, in the presence of a masking noise in 2 different conditions: noise and pure tone are fed in phase to both ears; and pure tone is fed in phase to both ears, with noise in inverted phase in one of the ears. This test was also performed at $50 \mathrm{dBSL}$ and/or with the most comfortable loudness level, in binaural condition. The subjects were instructed to say "yes" when they heard the pure tone, and "no" when they heard only the noise. The result was obtained by subtracting the threshold between the two conditions. The MLD was considered normal in the presence of differences in thresholds greater than or equal to $10 \mathrm{~dB}$ between the signal/noise conditions being checked. ${ }^{21}$

For the electrophysiological assessment, the subjects were comfortably seated in a reclining chair. After that, their skin was cleaned with NUPREP abrasive gel on the parts of their bodies where the electrodes would be placed. The electrodes were fixed with MAXXI FIX electrolytic paste, and microporous bandage, in the following positions: active electrode $(\mathrm{Fz})$ at the central portion and top of the forehead, grounding electrode $(\mathrm{Fpz})$ at the central portion and bottom of the forehead, and the reference electrodes fixed on left (M1) and right (M2) mastoid portions.

Electrode impedance values were kept equal to or lower than $3 \mathrm{kOhms}$; they were checked before, at the beginning and during all examinations. Both electrophysiological tests were performed by means of the Intelligent Hearing Systems (IHS) device (model "SmartEP", Intelligent Hearing Systems, USA) and insert earphones.

The click-evoked $A B R$ was performed in a recording window of $25 \mathrm{~ms}$, in the intensity of 80 decibels above normal adult hearing level $(\mathrm{dBnHL})$, with rarefied polarity, presentation speed of $27.7 / \mathrm{s}, 100 \mathrm{~Hz}$ low-pass filter and $3,000 \mathrm{~Hz}$ high-pass filter, repetition rate of $100.0 \mathrm{~K}$ and duration of $1,000 \mu \mathrm{s}$. The criteria for identifying the integrity of the auditory pathway were the presence of waves I, III and V, and the analysis of latency and interpeak intervals with reproducibility of tracings, following the normal parameters proposed. ${ }^{22}$ The minimum number of sweeps was 2,048 , and the number of artifacts did not exceed $10 \%$ of this figure.

Regarding the speech-evoked ABR, the stimulus used was the syllable /da/ with 40 milliseconds (stimulus provided by the manufacturer of the equipment used in this study), at the intensity of $80 \mathrm{dBnHL}$ in the right ear, with registration of a window of $60 \mathrm{~ms}$, low-pass filter of $100 \mathrm{~Hz}$ and high-pass filter of $3,000 \mathrm{~Hz}$, speed of $125 \mu \mathrm{s}$, rate of $11.10 / \mathrm{s}$ and electroencephalogram $30 \%$, with alternate polarity, and an average of 3,000 sweeps from 3 scans of 1,000 sweeps with an analysis of the wave resulting from a sum of these scans. Based on the same criteria of the click-evoked ABR, the tracings that were considered were only the ones in which the number of artifacts did not exceed $10 \%$ of the number of sweeps.

It should be noted that there were no studies in the literature reviewed involving speech-evoked ABR in hearing loss measured by the IHS device. Therefore, it was a methodological choice to link the neural representation of 3 stimulations of 1,000 sweeps with a similarity in the resulting wave, latency and morphology. Thus, the V, A, C, D, E, F, and $O$ waves were marked. The $O$ wave was the last to be marked, and there was no trough after it, following the morphology of the speech-evoked ABR in other previously normalized equipment. The test was considered abnormal when a wave was absent or its latency was outside the expected standard deviation (SD).

A study performed with 60 normal listeners ${ }^{23}$ aged between 18 and 35 years was used as a reference for marking the waves. The present study also used the same analysis for marking the tracings, and found the following latencies and SD: $\mathrm{V}$ wave $=7.59 \mathrm{~ms}(\mathrm{SD}=2.17 \mathrm{~ms}) ;$ A wave $=9.28 \mathrm{~ms}$ $(\mathrm{SD}=2.86 \mathrm{~ms}) ; \quad$ C wave $=18.85 \mathrm{~ms}(\mathrm{SD}=3.13 \mathrm{~ms})$; D wave $=27.53 \mathrm{~ms}(\mathrm{SD}=4.9 \mathrm{~ms}) ; \mathrm{E}$ wave $=34.76 \mathrm{~ms}$ $(\mathrm{SD}=4.59 \mathrm{~ms}) ; \mathrm{F}$ wave $=43.92 \mathrm{~ms}(\mathrm{SD}=5.13 \mathrm{~ms})$; and O wave $=53.91 \mathrm{~ms}(\mathrm{SD}=4.59 \mathrm{~ms})$.

The markings of the tests were performed together by three researchers and, subsequently, two female raters (speech therapists) performed their markings blindly and separately. The three tracings were compared, and the markings used in the statistical analysis had to agree on at least two of the markings.

The Pearson correlation coefficient was used as the statistical method to measure the degree of relation between the tests for quantitative values. A significance level of 0.10 (10\%) was used - a little above the commonly used level of $0.05(5 \%)$ - because of the small size of the sample. A positive correlation means that as a variable increases its value, the variable correlated to the former also increases proportionately. By contrast, a negative correlation implies that the variables are inversely proportional, that is, as one increases, the other decreases, or vice versa. The value of $80 \%$ was considered as indicative of an excellent correlation.

\section{Results}

The sample was composed of 8 subjects, 5 women and 3 men, aged between 46 and 58 years. - Table 1 shows the quantitative variables of the present study relative to age, auditory thresholds, behavioral tests and waves of the speech-evoked $A B R$. One can see that the V-A complex (onset) and the $O$ wave (offset) were identified in the tracings of all subjects. In addition to the data described in - Table 1, it should be emphasized that all subjects showed waves I, III and V in the click-evoked ABR, although most latencies were increased.

- Table 2 shows important data on the performance of the subjects in the different tests applied. It should be noted that all subjects showed normality in the MLD test and in most of the RGDT test. However, the speech-evoked ABR 
Table 1 Descriptive statistics for the quantitative variables of the study conducted with individuals with hearing loss: age, tritonal mean $(0.5-2 \mathrm{kHz})$, mean of $2 \mathrm{kHz}, 3 \mathrm{kHz}$ and $4 \mathrm{kHz}$, behavioral tests and waves of the speech-evoked auditory brainstem response

\begin{tabular}{|l|l|l|l|l|l|}
\hline Descriptive & N & Mean & $\begin{array}{l}\text { Standard } \\
\text { Deviation }\end{array}$ & Min & Max \\
\hline Age & 8 & 54.8 & 3.8 & 46.0 & 58.0 \\
\hline $\begin{array}{l}\text { Tritonal mean } \\
(0.5-2 \mathrm{kHz})\end{array}$ & 8 & 25.6 & 7.1 & 16.6 & 31.7 \\
\hline Mean of 2-4 kHz & 8 & 35.0 & 5.0 & 25.0 & 40.0 \\
\hline RGDT & 8 & 13.8 & 11.4 & 2.8 & 33.8 \\
\hline MLD & 8 & 13.3 & 5.5 & 10.0 & 26.0 \\
\hline PEAK V & 8 & 8.9 & 2.3 & 5.9 & 12.1 \\
\hline Trough A & 8 & 11.4 & 3.5 & 7.6 & 17.4 \\
\hline Trough C & 7 & 21.7 & 2.8 & 17.9 & 26.1 \\
\hline Trough D & 7 & 29.5 & 4.4 & 20.3 & 33.3 \\
\hline Trough E & 7 & 38.1 & 3.7 & 31.4 & 41.0 \\
\hline Trough F & 7 & 47.4 & 5.0 & 40.5 & 53.8 \\
\hline Trough O & 8 & 55.9 & 3.3 & 48.8 & 58.8 \\
\hline
\end{tabular}

Abbreviations: Max, maximum; Min, minimum; MLD, Masking Level Difference; N, number of individuals; RGDT, Random Gap Detection Test.

was altered in all subjects, since, when one of the portions (onset or FFR) showed no wave or latency outside the standard deviations expected, all the examination was considered to be altered.
Table 2 Normality and change in behavioral tests in speechevoked brainstem auditory response in general and separately between the portions onset and frequency-following response

\begin{tabular}{|l|l|l|l|l|}
\hline \multirow{2}{*}{} & \multicolumn{2}{|l|}{ Changed } & \multicolumn{2}{l|}{ Normal } \\
\cline { 2 - 5 } & N & $\%$ & N & $\%$ \\
\hline RGDT & 3 & 37.5 & 5 & 62.5 \\
\hline MLD & 0 & 0.0 & 8 & 100.0 \\
\hline ABR (ONSET) & 3 & 37.5 & 5 & 62.5 \\
\hline ABR (FFR) & 8 & 100.0 & 0 & 0.0 \\
\hline ABR (SPEECH) & 8 & 100.0 & 0 & 0.0 \\
\hline
\end{tabular}

Abbreviations: ABR, auditory brainstem response; FFR, frequency-following response; MLD, Masking Level Difference; $N$, number of individuals; RGDT, Random Gap Detection Test.

- Table 3 shows the correlation between all the waves of the speech-evoked ABR and the behavioral tests, as well as the correlation between the components of the speech-evoked ABR. There were no statistically significant values between the electrophysiological test and the behavioral tests. However, this correlation can be seen between the waves of the speechevoked ABR: Peak V and Trough A, Trough D and Trough F. Such correlations are positive, indicating that the increase of a variable implies an increase in another and vice versa. The two correlations are classified as "great" according to the statistical test Pearson correlation coefficient.

-Fig. 1 also shows the morphology and the marking of the resulting wave of the speech-evoked ABR in the IHS device in an individual with hearing loss.

Table 3 Correlation between the behavioral tests and the waves of the speech-evoked auditory brainstem response

\begin{tabular}{|c|c|c|c|c|c|c|c|c|c|}
\hline & & Peak V & Trough A & Trough C & Trough D & Trough E & Trough F & Trough 0 & MLD \\
\hline \multirow[t]{2}{*}{ Trough A } & Corr (r) & $94.6 \%$ & & & & & & & \\
\hline & $p$-value* & $<0.001$ & & & & & & & \\
\hline \multirow[t]{2}{*}{ Trough C } & Corr $(r)$ & $52.3 \%$ & $53.6 \%$ & & & & & & \\
\hline & $p$-value ${ }^{*}$ & 0.229 & 0.215 & & & & & & \\
\hline \multirow[t]{2}{*}{ Trough D } & Corr (r) & $0.0 \%$ & $17.9 \%$ & $54.3 \%$ & & & & & \\
\hline & $p$-value* & 1.000 & 0.702 & 0.266 & & & & & \\
\hline \multirow[t]{2}{*}{ Trough E } & Corr $(r)$ & $14.4 \%$ & $7.1 \%$ & $60.0 \%$ & $57.1 \%$ & & & & \\
\hline & $p$-value ${ }^{*}$ & 0.758 & 0.879 & 0.208 & 0.180 & & & & \\
\hline \multirow[t]{2}{*}{ Trough F } & Corr (r) & $-12.6 \%$ & $0.0 \%$ & $20.0 \%$ & $82.1 \%$ & $60.7 \%$ & & & \\
\hline & $p$-value ${ }^{*}$ & 0.788 & 1.000 & 0.704 & 0.023 & 0.148 & & & \\
\hline \multirow[t]{2}{*}{ Trough $\mathrm{O}$} & Corr (r) & $27.7 \%$ & $46.7 \%$ & $9.0 \%$ & $32.4 \%$ & $-18.0 \%$ & $48.7 \%$ & & \\
\hline & $p$-value* & 0.506 & 0.243 & 0.848 & 0.478 & 0.699 & 0.268 & & \\
\hline \multirow[t]{2}{*}{ MLD } & Corr $(r)$ & $19.3 \%$ & $48.5 \%$ & $41.8 \%$ & $26.2 \%$ & $-39.3 \%$ & $-7.5 \%$ & $51.4 \%$ & \\
\hline & $p$-value* & 0.648 & 0.223 & 0.350 & 0.570 & 0.383 & 0.873 & 0.193 & \\
\hline \multirow[t]{2}{*}{ RGDT } & Corr $(r)$ & $29.9 \%$ & $7.1 \%$ & $-46.4 \%$ & $-17.9 \%$ & $3.6 \%$ & $-14.3 \%$ & $-25.2 \%$ & $-52.4 \%$ \\
\hline & $p$-value* & 0.471 & 0.867 & 0.294 & 0.702 & 0.939 & 0.760 & 0.548 & 0.183 \\
\hline
\end{tabular}

Abbreviations: Corr(r), correlation; MLD, Masking Level Difference; RGDT, Random Gap Detection Test.

Note: *Pearson correlation test. 


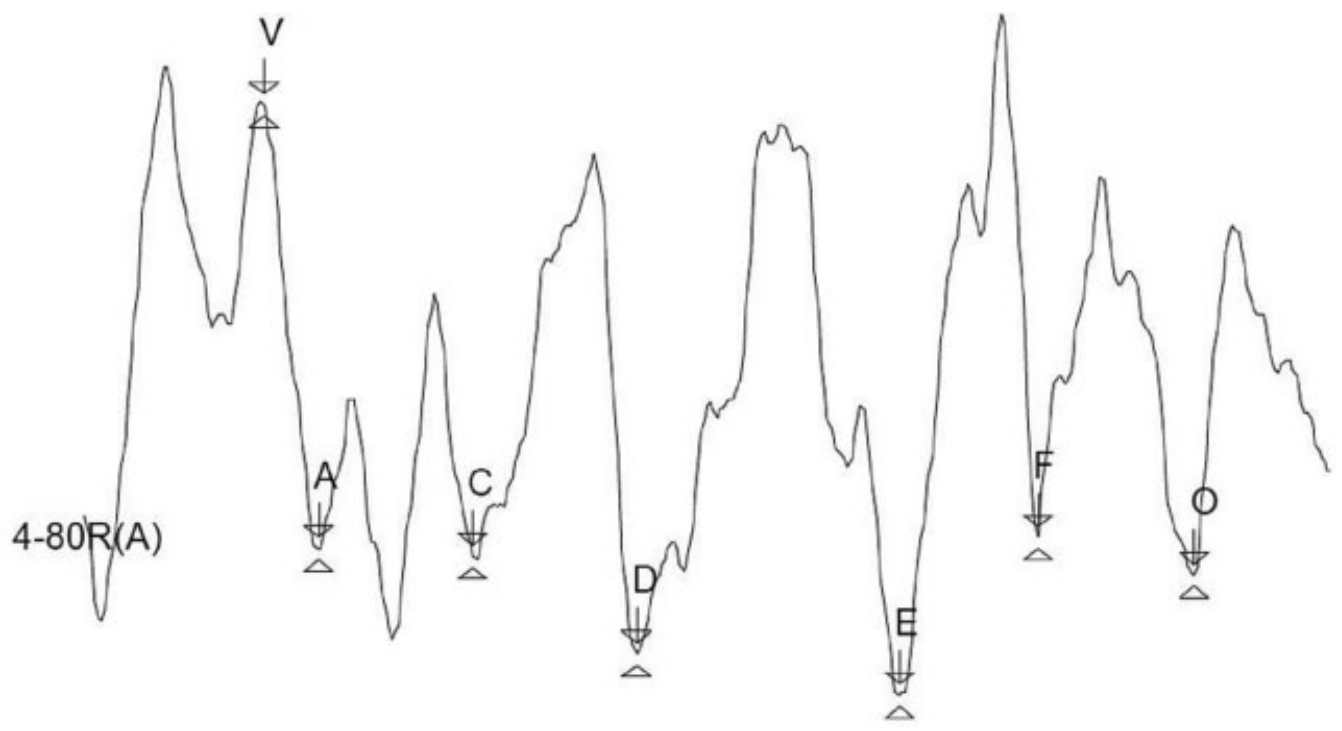

Fig. 1 Record of auditory brainstem response in an Intelligent Hearing Systems Smart-EP device using verbal stimuli in individuals with mild hearing loss.

\section{Discussion}

According to a recent study, the most often studied population for speech-evoked ABR is made up of young adults and/ or healthy adults. ${ }^{24}$ This lack of research involving individuals with hearing loss leads to an increasing need for studies on the IHS equipment, as it is widely used both for clinical-audiological diagnoses and by the academic community. Even though the present research has a small sample, it can describe the presence of the waves of the speech-evoked ABR in adult subjects with up to moderate hearing loss (-Table $\mathbf{1}$ ).

This finding was already expected, because although the generating sites had not yet been defined, the literature shows that the sustained portion of the speech-evoked ABR already assesses the auditory pathway at the subcortical level and, therefore, it is less influenced by peripheral loss. ${ }^{16}$ It is understood that if the absence of waves was related to the hearing loss, this absence would begin at the V-A complex, that is, still in a lower portion of the auditory pathway. However, the presence of the $V$ and $A$ waves can be seen in all evaluated subjects. Therefore, it is suggested that this absence of waves is related to an auditory processing disorder, which may not have been captured by the behavioral tests RGDT and MLD, because they assess an important portion of the brainstem, which is lower, nevertheless. ${ }^{1}$

As mentioned before, each study on the IHS device needs to adopt a method for marking the waves of the speechevoked ABR, since there is still no standardization for it in this device. Thus, given the choice of joining reproducibility in neural representation, latency analysis ${ }^{23}$ and morphology, the resulting standard deviation values were higher than expected. After the completion of this study, it is understood that the morphological issue does not follow exactly the one found in another equipment, hence latency should be the primary marker for the analysis of the speech-evoked ABR, as already mentioned by another renowned study. ${ }^{25}$
Importantly, all subjects showed waves I, III and V of the click-evoked ABR; however, most latencies were increased, which is also indicative of an alteration in the neural conduction of sound. ${ }^{26}$ These data are in agreement with a study $^{27}$ that reported the ability of the auditory pathway in responding to the click-evoked ABR even with an up to moderate level of hearing loss. Subsequently, other authors ${ }^{28}$ showed that even with the onset of the waves, an alteration in the auditory processing can be detected by the delay of the latencies.

An interesting fact found in this study is that the results of the click-evoked ABR corroborate those found for the speechevoked ABR, as both evaluations suggest an alteration in the auditory processing, even though they are not comparable. This fact disagrees with two recent studies that found no relation between these electrophysiological assessments. The first study ${ }^{29}$ described the absence of a statistically significant relation in the click-evoked ABR, between a group composed of 18 children with typical development and one group composed of 11 students with learning difficulties. However, there was a statistically significant difference in the latency of the D wave of the speech-evoked ABR, with higher values for the study group. The second research, ${ }^{30} \mathrm{a}$ case study, sought to report click-evoked and speech-evoked auditory brainstem responses in a child with mild, unilateral sensorineural hearing loss. It also found normality on the click-evoked ABR. However, there was an increased latency in the $C$ and $D$ waves of the speech-evoked ABR.

As previously stated, the findings of the present study do not agree with the studies mentioned before, as alterations were found for the click-evoked ABR, although similarly to speech-evoked ABR. Nevertheless, all studies reinforce the idea that the speech-evoked ABR may be a useful tool to assess the central auditory system accurately.

Another fact that should be emphasized is that all individuals presented alterations in the speech-evoked ABR, with the largest part presenting in the FFR (-Table 2). This 
research has a great advantage over other studies ${ }^{7,31}$ that investigated only the onset; those studies did not identify possible alterations in the speech-evoked ABR. The latencies that correspond to the FFR portion are already considered subcortical, between $18 \mathrm{~ms}$ and $53 \mathrm{~ms},{ }^{23}$ which provides information on the auditory pathway that is not encompassed by the click-evoked ABR.

Conversely, all subjects showed normality in the MLD test (-Table 2). The main hypothesis for this fact is that the generating site for the selective attention skill is located in the lower brainstem. ${ }^{4}$ It is thus clear, in the present study, that the speech-evoked ABR does not depend on these structures. Therefore, these subjects have a physiological alteration in the auditory pathway, as detected by the waves of the speech-evoked ABR, but they have normal responses in the behavioral test. Thus, they show a division of neural function in the brainstem. A recent study ${ }^{23}$ sought to relate the results of 30 adult subjects with normal hearing, with complaints of difficulty in speech comprehension, in the MLD test and in the speech-evoked ABR. It also found a higher number of alterations in the electrophysiological assessment. Again, this fact shows the independence of the structures of the auditory pathway.

Unlike in the MLD test, the temporal aspects, as assessed by the RGDT test, had more similar results to those of the speech-evoked ABR, but they were not equivalent ( - Table 2). However, this divergence between the aforementioned physiological and behavioral responses cannot be disregarded, bearing in mind that the auditory pathway does not respond exactly the same way to both stimuli.

Some authors have determined the importance of temporal aspects in speech understanding, because their codification begins in the cochlear nucleus and extends up to the highest portions of the central auditory system. ${ }^{1}$ It is understood that this fact may have generated a small but important number of alterations in the RGDT, when compared with the speech-evoked ABR.

Following the objective of the study, correlating all waves of the speech-evoked ABR and the behavioral tests separately ( - Table 3) resulted in no positive correlation between them. Again, this shows the impartiality of the physiological and behavioral responses for processing tests that involve the lower brainstem, in which temporal resolution and selective attention begin.

However, when the waves of the speech-evoked ABR were correlated, there was a statistical significance between the $V$ and $A$ waves, that is, the increase in the latency of the $V$ wave implies an increase in the latency of the A wave, which is expected, as they form a complex called onset or transient portion. ${ }^{7}$ It should also be emphasized that in subjects with hearing loss, there was a significant correlation between the $\mathrm{D}$ and $\mathrm{F}$ waves, as well as a tendency for significance among the $E$ and $F$ waves. These findings stress the importance of the analysis of the FFR portion in subjects with speech processing difficulty and in the complement of the physiological assessment of the brainstem in subjects with hearing loss.

The present study, as well as others previously described in the literature, ${ }^{18,31}$ seeks to show the importance of research on the speech-evoked ABR even in subjects who have normal results in behavioral evaluations of auditory processing. This procedure can be performed in subjects with and without processing difficulties, because one can analyze the waves, identify normality/alteration, and follow-up the physiological function of the auditory pathway when the patient is submitted, for example, to a process of auditory training or sound amplification. This could not happen if the subjects were evaluated only with the click-evoked ABR.

This study not only compared the speech-evoked ABR and various behavioral tests, but also characterized its tracing for hearing loss, using the IHS device (-Fig. 1). This is of utmost importance in the present work, because there were no studies in the literature that described such an electrophysiological assessment in this population. This can be used as the basis for future researches whose goal is to expand the electrophysiological study for different pathologies. It is suggested that further research could relate other auditory skills with the speech-evoked ABR, as there was no significant correlation with the skills covered in this study.

\section{Conclusion}

The findings of speech-evoked ABR-speech could be correlated with the behavioral tests RGDT and MLD. However, there was no statistically significant correlation between the tests. This shows that the waves of the speech-evoked ABR do not depend only on the behavioral skills of temporal resolution and selective attention.

\section{References}

1 Teixeira CF, Griz SMS. Sistema Auditivo Central In: Bevilacqua MC, Martinez MAN, Balen AS, et al. Tratado de Audiologia. São Paulo: Santos; 2011:17-27

2 Pereira LD, Schochat E. Testes auditivos comportamentais para avaliação do processamento auditivo central. Barueri. Pro Fono 2011:82p

3 Frota S, Pereira LD. Processamento auditivo: estudo em crianças com distúrbios da leitura e da escrita. Psicopedagogia 2010; 27(83):214-222

4 Paula PS, Frota S, Felipe L. Masking threshold differential (MLD): Pilot Study. Int. Arch. Otorhinolaryngol. 2012;16(01):102

5 Hall JW III. Application of ABR in objective assessment of infant hearing. Audiology Online [internet] 2013. Avaliable at: http:// www.audiologyonline.com Accessed: october 05, 2016

6 Matas CG. Audiometria de tronco cerebral. In: Carvallo RMM. Fonoaudiologia: informação para a formação. São Paulo: Guanabara Koogan; 2003:43-56

7 Rocha CN, Filippini R, Moreira RR, Neves IF, Schochat E. Brainstem auditory evoked potential with speech stimulus. Pro Fono 2010; 22(04):479-484

8 Russo N, Nicol T, Musacchia G, Kraus N. Brainstem responses to speech syllables. Clin Neurophysiol 2004;115(09):2021-2030

9 Dhar S, Abel R, Hornickel J, et al. Exploring the relationship between physiological measures of cochlear and brainstem function. Clin Neurophysiol 2009;120(05):959-966

10 Basu M, Krishnan A, Weber-Fox C. Brainstem correlates of temporal auditory processing in children with specific language impairment. Dev Sci 2010;13(01):77-91

11 Skoe E, Kraus N. Auditory brain stem response to complex sounds: a tutorial. Ear Hear 2010;31(03):302-324 
12 Filippini R, Schochat E. Potenciais evocados auditivos de tronco encefálico com estímulo de fala no transtorno do processamento auditivo. Bras J Otorrinolaringol 2009;75(03):449-455

13 Hornickel J, Kraus N. Objective Biological Measures for the Assessment and Management of Auditory Processing Disorder. Curr Pediatr Rev 2011;7(03):252-261. doi:10.2174/157339611796548438

14 Filippini R, Befi-Lopes DM, Schochat E. Efficacy of auditory training using the auditory brainstem response to complex sounds: auditory processing disorder and specific language impairment. Folia Phoniatr Logop 2012;64(05):217-226

15 Rocha-Muniz CN, Befi-Lopes DM, Schochat E. Investigation of auditory processing disorder and language impairment using the speech-evoked auditory brainstem response. Hear Res 2012;294(1-2):143-152

16 Anderson S, Parbery-Clark A, White-Schwoch T, Kraus N. Auditory brainstem response to complex sounds predicts self-reported speech-in-noise performance. J Speech Lang Hear Res 2013; 56(01):31-43

17 Banai K, Abrams D, Kraus N. Sensory-based learning disability: Insights from brainstem processing of speech sounds. Int J Audiol 2007;46(09):524-532

18 Johnson KL, Nicol TG, Kraus N. Brain stem response to speech: a biological marker of auditory processing. Ear Hear 2005;26(05): 424-434

19 Lloyd LL, Kaplan H. Audiometric interpretation: a manual of basic audiometry. Baltimore: University Park Press; 1978: $12-17$

20 Ziliotto K, Pereira LD. Random gap detection test in subjects with and without APD. In: Journal of American Academy of Audiology - Annual Convention and Exposition 2005; (17th): 30

21 Wilson RH, Moncrieff DW, Townsend EA, Pillion AL. Development of a $500-\mathrm{Hz}$ masking-level difference protocol for clinic use. J Am Acad Audiol 2003;14(01):1-8
22 Weich TM, Tochetto TM, Seligman L. Brain stem evoked response audiometry of former drug users. Bras J Otorrinolaringol 2012; 78(05):90-96

23 Silva DD. Funcionalidade da via auditiva em nível de tronco encefálico em indivíduos jovens com e sem queixa de compreensão de fala [dissertação]. Santa Maria: Universidade Federal de Santa Maria; 2016

24 Sanfins MD, Colella-Santos MF. A review of the clinical applicability of speech-evoked auditory brainstem responses. J Hear Sci 2016;6(01):9-16 DOI: 10.17430/897811

25 Skoe E, Krizman J, Anderson S, Kraus N. Stability and plasticity of auditory brainstem function across the lifespan. Cereb Cortex 2015;25(06):1415-1426

26 Fernandes LCBC, Gil D, Maria SLS, et al. Potencial evocado auditivo de tronco encefálico por via óssea em indivíduos com perda auditiva sensorioneural. Rev. CEFAC 2012;15(03):538-545

27 Momensohn-Santos TMM, Russo ICP. (orgs). Prática da audiologia clínica. 6 ed. São Paulo: Cortez; 2007:291-310

28 Pfeiffer M, Frota S. Processamento auditivo e potenciais evocados auditivos de tronco cerebral (BERA). Rev. CEFAC 2009;11(01):31-37

29 Sanfins MD, Borges LR, Ubiali T, Colella-Santos MF. Speech-evoked auditory brainstem response in the differential diagnosis of scholastic difficulties. Bras J Otorrinolaringol 2015;83(01): 112-116 DOI: 10.1016/j.bjorl.2015.05.014

30 Ubiali T, Sanfins MD, Borges LR, et al. Relato de caso: Potenciais Evocados Auditivos de Tronco Encefálico (PEATE) com estímulos de fala e clique em um caso de perda auditiva neurossensorial de grau leve unilateral [internet] 2015 Avaliable at: http://www. audiologiabrasil.org.br/eiabauru2015/anais2015/resumos/ R0271-3.html Accessed: october 10, 2016

31 Rocha-Muniz CN, Filippini R, Neves-Lobo IF, et al. Can speechevoked Auditory Brainstem Response become a useful tool in clinical practice? CoDAS 2016;28(01):77-80 